\title{
FURTHER STUDIES ON THE NUCLEAR CHROMATIN OF MORPHOLOGICALLY ABNORMAL BULL SPERMATOZOA
}

\author{
B. L. GLEDHILL \\ School of Veterinary Medicine, University of Pennsylvania, \\ New Bolton Center, Kennett Square, Pa. 19348, U.S.A.
}

(Received 7th December 1971, accepted 31st December 1971)

In ejaculated semen from highly fertile bulls, abnormal head forms constitute 5 to $20 \%$ of the total number of sperm heads, while even higher percentages are commonly found in ejaculates from bulls with certain types of reduced fertility. Intranuclear spaces and a granular appearance of the nuclear chromatin were the major abnormalities observed in a high percentage of spermatozoa from two infertile bulls (McCosker, 1969).

The organization of the DNA and nuclear proteins forming the deoxyribonucleoprotein complex (DNP) in the chromatin of deformed sperm heads has received little attention. Previous studies have demonstrated that most morphologically abnormal sperm heads contain the same amounts of DNA as their normally shaped counterparts (Gledhill, 1966a). Defects in the binding of nuclear protein to DNA, which probably occur during the process of chromatin aggregation in spermateliosis, have only recently been incriminated in the formation of certain misshapen sperm heads (Gledhill, Darżynkiewicz \& Ringertz, 1971). Their possible rôle in an instance of infertility was noted earlier (Gledhill, Gledhill, Rigler \& Ringertz, 1966a).

The present communication reports a study which had as its objective to determine if the DNA of abnormally shaped spermatozoa has a sensitivity to thermal denaturation that differs from that of normally shaped spermatozoa. The method used allows the analysis of molecular arrangements of DNA within intact, definable sperm heads. Such information has physiological importance as it relates to current work on the maturation of nuclear chromatin and could show mechanisms which might be involved in the differentiation of abnormal sperm heads.

Nine sexually mature and normally fertile dairy and beef bulls of varying ages ( $1 \frac{1}{2}$ to 15 years) and breeds were used. Spermatozoa from the testis and from the caput epididymidis were obtained in a manner previously described (Gledhill, 1966b). Spermatozoa were also obtained from the left vas deferens of two of the bulls (courtesy of Dr R. P. Amann, The Pennsylvania State University) at 1 and 3 days after cannulation by a modification of the method of Amann, Hokanson \& Almquist, (1963) and Sexton, Amann \& Flipse (1971). Ejaculated spermatozoa were collected with the aid of an artificial vagina. The criteria used for differentiating morphologically abnormal from normal 
sperm heads were those of Lagerlöf (1934), as adapted for this type of work by Gledhill (1966a).

Thermal denaturation of nuclear DNA in situ was measured according to the acridine orange procedure described earlier (Ringertz, Gledhill \& Darżynkiewicz, 1970). With this technique, the degree of denaturation is assessed by

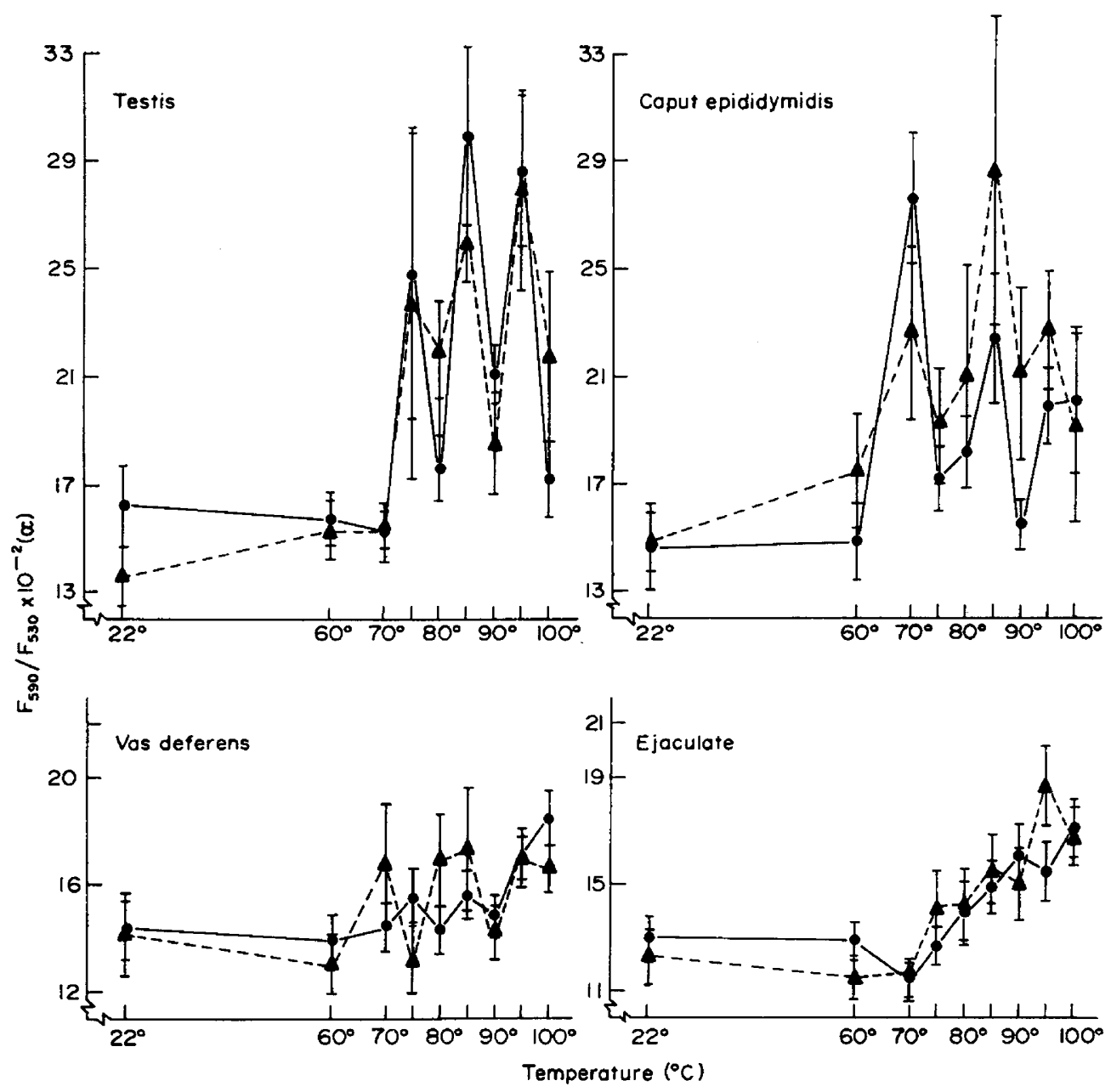

TExr-FIG. 1. Effect of heating on the $\mathbf{F}_{590} / \mathbf{F}_{530}$ ratio $(\alpha)$ of acridine orange-stained smears of bull spermatozoa obtained from testicle scrapes ( $N=2$ bulls, $n=20$ cells per experimental variant, i.e. temperature, cell morphology, site of origin), caput epididymidis $(\mathbf{N}=2, \mathbf{n}=20)$, vas deferens $(\mathbf{N}=2, \mathrm{n}=30)$ and ejaculates $(\mathbf{N}=3, \mathrm{n}=$ 30). The increase in $\alpha$ reflects the change from a double-stranded to a single-stranded state of the nuclear DNA. Morphologically normal (O) and abnormal ( $\Delta$ ) spermatozoa; the S.E.M. is represented by a vertical line.

microfluorimetry of samples previously treated at one of several temperatures between $22^{\circ}$ and $100^{\circ} \mathrm{C}$. As the incubation temperature increases, the doublestranded DNA is denatured and splits into single-stranded long chain polynucleotides. Since acridine orange binds in a monomer form to double-stranded 
DNA giving rise to a green fluorescence, and single-stranded (denatured) DNA binds the dye in an aggregated form giving rise to a red fluorescence, there is a shift towards red in the emission spectrum. By measuring the ratio between the amount of red and green fluorescence $\left(\mathrm{F}_{590} / \mathrm{F}_{530}=\alpha\right)$ emitted from individual sperm heads, it is possible to follow changes in the proportion of singleto double-stranded regions induced by heating. A melting-profile of the DNA may be constructed by plotting $\alpha$ against temperature. In the present experiments, an increase in $\alpha$ indicates not only an increased amount of red fluorescence but a reduction in green fluorescence as well since the amount of DNA remains essentially constant.

Following acridine orange staining, the cells were examined in a Zeiss Universal Large Fluorescence Microscope. Excitation light at $365 \mathrm{~nm}$ was provided by filtering light from an Osram $\mathrm{HBO} 100 \mathrm{~W} / 2$ mercury lamp through Schott filters BF3, KG1 and BG38. The excitation beam was thereafter directed as reflected light through an F1 reflector. Barrier filters (Schott) for essentially monochromatic light at 530 and $590 \mathrm{~nm}$ were interposed between the cells and a RCA-1-P28 photomultiplier. Total fluorescence, registered as scale divisions on a Zeiss Indicator Unit (47-42-05), was corrected for background as described earlier (Gledhill et al., 1966b).

Text-figure 1 shows composite melting-profiles obtained for morphologically normal and abnormal sperm heads. For each site, the similarity of these profiles clearly indicates that there is no difference between normally and abnormally shaped sperm heads in the resistance of their DNA to thermal denaturation. The progressive increase in stability against heat denaturation with advancing maturity reported earlier (Gledhill, 1971) for normally shaped germinal cells again was evident. There was a parallel development of this characteristic in abnormally formed heads.

For samples of both normal and abnormal spermatozoa from the testis and caput epididymidis, the large values for the standard error of the mean at each temperature indicate a greater heterogeneity of response to treatment when compared to spermatozoa from the vas deferens and ejaculate samples. While more information is being gathered on this point (Gledhill \& Amann, unpublished data), preliminary data substantiates the premise that molecular alteration of sperm DNP is largely completed in the upper portions of the epididymis.

These studies were supported by funds from the U.S. Public Health Service (HD-03577). The author thanks Miss Nini A. Rosenfeld for technical assistance, Dr R. P. Amann for samples from his cannulated bulls and Dr V. K. Ganjam, Dr R. P. Amann and Professor W. C. D. Hare for reading and criticizing the manuscript.

\section{REFERENCES}

Amann, R. P., Hokanson, J. F. \& Almquist, J. O. (1963) Cannulation of the bovine ductus deferens for quantitative recovery of epididymal spermatozoa. F. Reprod. Fert. 6, 65.

GLedHILl, B. L. (1966a) Studies on the DNA content, dry mass and optical area of morphologically normal and abnormal bull spermatozoal heads. Acta vet. scand. 7, 1. 
GLedHill, B. L. (1966b) Studies on the DNA content, dry mass and optical area of bull spermatozoal heads during epididymal maturation. Acta vet. scand. 7, 131.

GLEDhiLl, B. L. (1971) Changes in deoxyribonucleoprotein in relation to spermateliosis and the epididymal maturation of spermatozoa. 7. Reprod. Fert., Suppl., 13, 77.

Gledhill, B. L., Darżynkiewicz, Z. \& RingertZ, N. R. (1971) Changes in deoxyribonucleoprotein during spermiogenesis in the bull: increased $\left[{ }^{3} \mathrm{H}\right]$ actinomycin $D$ binding to nuclear chromatin of morphologically abnormal spermatozoa. F. Reprod. Fert. 26, 25.

GLedhill, B. L., Gledhill, M. P., Rigler, R., JR \& Ringertz, N. R. (1966a) Atypical changes of deoxyribonucleoprotein during spermiogenesis associated with a case of infertility in the bull. 7. Reprod. Fert. 12, 575.

Gledhill, B. L., Gledhill, M. P., Rigler, R., Jr. \& Ringertz, N. R. (1966b) Changes in deoxyribonucleoprotein during spermiogenesis in the bull. Expl Cell Res. 41, 652.

LAGERLör, N. (1934) Morphologische Untersuchungen über Veränderungen im Spermabild und in den Hoden bei Bullen mit verminderter oder aufgehobener Fertilität. Acta path. microbiol. scand. Suppl. 19.

MCCosker, P. J. (1969) Abnormal spermatozoan chromatin in infertile bulls. J. Reprod. Fert. 18, 363.

Ringertz, N. R., Gledhill, B. L. \& Darżynkiewicz, Z. (1970) Changes in deoxyribonucleoprotein during spermiogenesis in the bull: sensitivity of DNA to heat denaturation. Expl Cell Res. 62, 204.

Sexton, T. J., Amann, R. P. \& Flipse, R. J. (1971) Free amino acids and protein in rete testis fluid, vas deferens plasma, accessory sex gland fluid, and seminal plasma of the conscious bull. $\mathcal{F}$. Dairy Sci. 54, 412. 